\title{
Arogyakrpata - A Natural Protection
}

\author{
Saloni Jain
}

National Institute of Fashion Technology, Kolkata.

To Cite this Article

Saloni Jain, "Arogyakrpata - A Natural Protection", International Journal for Modern Trends in Science and Technology, 6(9S): 147-153, 2020.

\section{Article Info}

Received on 25-August-2020, Revised on 08-September-2020, Accepted on 12-September-2020, Published on 18-September-2020.

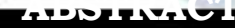

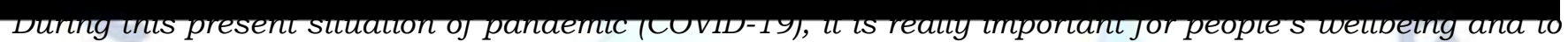
take care of their health and immunity. Since no vaccine has been discovered to cure/ effectively available to the people, the effect of the virus is outnumbering the other illness of previous pandemic.

The research is designed towards the wellbeing of the Covid-affected population by designing bed linen and medicated patient's robe.

Therefore, the aim of the design here is to solve the area of design problem of Corona affected patients and recovering population in quarantine, either in medical facility centers or at home isolation.

The design of ArogyakrpaTa - textile products includes products likes bed cover, cushion and Patient's robe and overall/ apron for care givers.

The design solutions are aimed to address the safety and health-aspect of the concern patients.
}

\section{Using medicinal plants}

Improving the immunity of a person by giving some level of protection from falling sick from even a normal bacteria or flu. Using herbal medicinal plants and their benefits by dying and covering to create a home collection/wearable piece/ fashion which helps not only as a protection but also it will develop a goodaroma on the skin, and one will notice immunity creating in the body. Also the absence of harsh chemicals in terms of dye stuff and textile finishing, is going to be beneficial for long time use, specially most of the skin contact time with patient's bed sheet and pillow cover will be more than 12 to 24 hours for initial weeks and approx. 14 hours for the laterperiod of the time.The fibers of the material used to develop the fabric are obtained naturally, is environment friendly, sustainable and biodegradable. The fibers are long, soft, shiny and can be spun into coarse, strong threads and also is biodegradable. The medicinal dye can be used after the yarn process or after the fabric production process. Protection masks can also be developed with it.

KEYWORDS:health \& immunity, medicinal dye, sustainable, protection, Medicaid textile

\section{INTRODUCTION}

The worldwide demand for natural dyes is nowadays of great interest due to the increased awareness on therapeutic properties of natural dyes in public. Natural dyes are derived from naturally occurring sources such as plants, insects, animals and minerals. They are not only used to impart color to an infinite variety of materials such as textiles, paper, wood etc. but also, they are widely used in cosmetic, food and pharmaceutical industry. 
They have wide range of medicinal importance in pharmaceutical industry. Some of them gives natural colorants by extraction process. These dyes are applied as a green and sustainable dyeing process due to their biocompatibility, low toxicity, abundant availability, antibacterial activity, deodorizing performance, UV protection, and eco-friendliness.

These benefits can be used in the present-day scenario of covid'19 pandemic time. Where it is really important for an individual to stay healthy in order to fight with the virus including the hospital members, staffs and the patients.

\section{OBJECTIVE OF THE STUDY}

To find out the design solution $\&$ develop a product which will be directly used by the Covid'19 patients in hospitals during this pandemic.

\section{CONCEPT}

To develop a bedding collection for the covid'19 patients with the help of medicinal plants/herbs.

During the early infection, in the initial stages of the person infected with the virus, mild symptoms are seen that may be confused with a common cold or flu.Eventually leading it to hyper activated immune system which may cause injury to the heart, kidneys, and other organs of the body. Therefore, idea is to create the textile which has antibacterial, antifungal, and the ability to fight with bacteria and flue and other issues such as headaches and digestive disorders, etc. It will also help in boosting the immune system of a person and develop a good aroma on the skin. With the help of bed cover and pillows which are the most in contact with the patient during this time. It can also be used by the health workers in the hospitals as an inner garment in order them to boost their immune system and stay healthy around the patients.

Looking at the Indian climate and the humidity, it is planned to make an easy to wear open pattern patient robes are which is with a convenient tie/button closure at neck and waist which will be adjustable for the different body type of a person. It is planned to not restrict the movement of the body and should be breathable and comfortable to wear for long periods. Some of the characteristics of an ideal gown for the patients are, barrier effectiveness, functionality or mobility, comfort, strength, fit, biocompatibility, and protection. [13]

The fabric: Down and feathers must be filled into a tightly woven, but at the same time breathable shell. The shell must safely prevent the filling components (for instance parts of down and feathers) from penetrating the fabric. Furthermore, it shall support the properties of the filling materials such as regulation of humidity and breathability. [8]

On the other hand, no parts from outside (e. g. skin scales or house dust mites) should get into the filling. This aspect is crucial, since a top-quality fabric is the basis ensuring that the bedding article is suitable for house dust mite allergy sufferers.[8]Patients generally present for evaluation if they have an illness such as eczema, rhinitis, or asthma. These can be exacerbated by inhalation of dust mite allergen; eczema can be exacerbated by skin contact, given sensitization and sensitivity.Because exposure to dust mites also can trigger symptoms in non-sensitized individuals, sensitization per se is not the only criterion for possible morbidity from exposure. [9]

To ensure ideal sleeping comfort the shells must be breathable so that the humidity absorbed by the filling can be transmitted outwards. Cotton is the most suitable raw material forming the basis for shells and for the dust mite solution. Depending on the range of quality medium or long-stapled grades of maco cotton are employed. [8]

\section{DYES USED AND THEIR BENEFITS}

TURMERIC (Curcuma longa)- Also known as haldi in India has anti-inflammatory and antioxidantproperties. It has been used in Ayurvedic medicine for thousands of years. It isapplied on wounds, and it's believed to fight infection \&it has been proven to support the heart, brain, liver, nervous system, circulatory system...in fact there are very few parts of the body this root cannot care for. 
POMEGRANATE (Punicagranatum)- contains large quantity of tannin which shows antimicrobial activity. It has inhibitory effect on chemical induced carcinogenesis and cancer, and can be used as exogenous antioxidants, antibacterial effect of antibacterial.[2]

PAPPERMINT (Mentha $\times$ piperita)- Also known as pudina in India has Different parts of the plantincluding its leaves, flower, stem, bark, and seeds have been also used widely in traditional folk medicine as antimicrobial, carminative, stimulant, antispasmodic and for the treatment of various diseases such as headaches and digestive disorders.

The Key element: NEEM (Azadirachtaindica)- Neem leaf and its constituents have been demonstrated to exhibit immunomodulatory, anti-inflammatory, anti-hyperglycemic, antiulcer, antimalarial, antifungal, antibacterial, antiviral, antioxidant, anti-mutagenic and anti-carcinogenic properties.[4]Most of the parts of the plant such as fruits, seeds, leaves, bark and roots enclose compounds with recognized number of human ailments.Neem leaves comprises relatively important minerals required by the biochemicalsystem.[3][4]

\section{METHEDOLOGY}

Textiles come to our help in the everyday walk of life. Textiles are vulnerable to toxin and micro-organisms that cause infection and allergic reactions. Home textile products come in contact with the skin. Therefore, the idea is to make herbally treated fabricswith medicinal dyes and their benefits. Making herbal textile begins with $100 \%$ organic fabric with no chemical process involved while dyeing and processing the fabric. The fabric is passed through various stages of treatment before are turned into finished products.

When a person sleeps, the body releases hormones that can slow breathing, and relax other muscles in the body. This process can reduce inflammation and assist with healing. Therefore, the benefits of the textile will be most affective during that time.In this preparation of medicinal textile for a bedding collection, 4 medicinal herbs are used, i.e., Turmeric, Pomegranate skin, Peppermint, \& Neem.

Cotton is the purest form of cellulose that can be found in nature and excels the physical and chemical homogeneity of any other vegetable fiber. Cotton offers the positive property of being a naturally breathing fiber. I.e. it largely prevents the passage of fluids and water vapor pass.[5] With this property, cotton is also predestined for surgical gowns and drapes\& medical dresses. Wet state, cotton has a higher strength favorable for health care applications requiring skin contact.Spunlaced cotton of a low micronaire obtains a higher tensile strength but offers a stiffer touch than cotton of a high micronaire. Treated cotton, other than used in the medical industry, can also with good results for semi durable sheets napkins and tablecloths that can be washed 6-10 times. [5]Maco is an extra fine, silky sort of cotton (for instance Egyptian maco cotton) which is spun from an extra-long staple and more valuable than other grades of cotton. Fine threads are spun from Maco cotton which are suited for the production of most delicate tickings and cambric fabrics. A distinction is made between short-stapled (ca. $22 \mathrm{~mm}$ ), medium-stapled $(22-29 \mathrm{~mm})$ and long-stapled $(30-35 \mathrm{~mm})$ cotton. The long-stapled sorts of cotton offer top quality fabrics. [8]

Three coats of neem treatment are given to the textile so ensure the most of the effect. Also, in the hospitals, the bed covers are changed every day or every alternative day, therefore the bedcovers can be used more than one time due to its qualities. And the health workers can also use this as their inner garment having the same benefits. The topical application of neem leaf to UVB-irradiated hairless mice was shown to be very effective in treating the symptoms of skin connected/related problems such as wrinkles, thickening, water loss, erythema, etc. [12]

\section{V.A: DYE TREATMENT}

\section{V.A. 1. Preparation of the fabric:}

- $100 \%$ cotton fabric is taken.

- Then the fabric is desized by dissolving a little soda ash and a little regular fabric detergent of dish wash soap depending on the gallon of boiling water taken. 
- Fabric is added in the half boil water for 15-20 min (depending on the length of the fabric).

- Drain and rinse when time's up.

\section{V.A. 2. Preparation of the dye:}

- Dye Material (Herbs/Plants)

3 Plants/Herbs are taken individually.

TURMERIC

PROMOGRANATE

PAPPERMINT

- Preparation of the solution

$40 \mathrm{~g}$ leaves are added to $80 \mathrm{ml}$ of water (1:2 leaves: water) $\&$ heated to $80^{\circ} \mathrm{C}$ for $40 \mathrm{~min}$ with addition of $1 \mathrm{gm}$ sodium calories $(5 \%)$. Then temperature was maintained because it was noticed that overheating caused charring of dye solution.

- After $40 \mathrm{~min}$ the aqueous dye solution was flattered, and the residual flowers were separated from the colored solution.

\section{V.A.3. Dying:}

- Prepared fabric is dipped in the dye solution with alum- mordent to fix the dye on a textile for a longer period of time.

- The fabric is being added in $40 \mathrm{ml}$ of dye solution and was kept for $30 \mathrm{~min}$. Fabric is gently moved around in the dye pot a few times to avoid blotchy results.

- After getting the desired color, fabric is taken out and is rinsed to remove the excess dye and kept to dry.

This process is followed for all the dyes used for this experiment.

\section{V.B: NEEM TREATMENT}

\section{V.B. 1. Preparation of Neem coating:}

The neem plant can be considered as a good sourceof natural dye with antimicrobial properties and can be used in dyeing and protective finishing of textile Fabrics

- $50 \mathrm{~g}$ Fresh neem leaves are taken with $500 \mathrm{ml}$ of distilled water and is to boil till the quantity of the water becomes half of amount taken.

Make sure the solution is not thick as we are planning to make a coating of the leaves with utmost advantage taken from it.

After minimum $30 \mathrm{~min}$ of boiling the leaves and achieving the desired solution, the leaves are separated from it into another vessel/container.

\section{V.B. 2. Treating the fabric with neem coating:}

Previously dyed different color fabrics are then treated 3 times in the solution to gain most of the benefit of the plant and can last for a longer period of time.

- The dyed fabrics are soaked in the neem solution. After 60 min the fabric is taken out and kept under the sun to dry.

After drying, the fabric is dipped in the solution again, this cycle is repeated three times to get the most benefit of the solution on the textile.

This process is done will all the three different dyed fabrics. You will notice the color difference on the fabric after each cycle to neem coating.(Figure-V.5-a, V.5-b, V.5-c) 


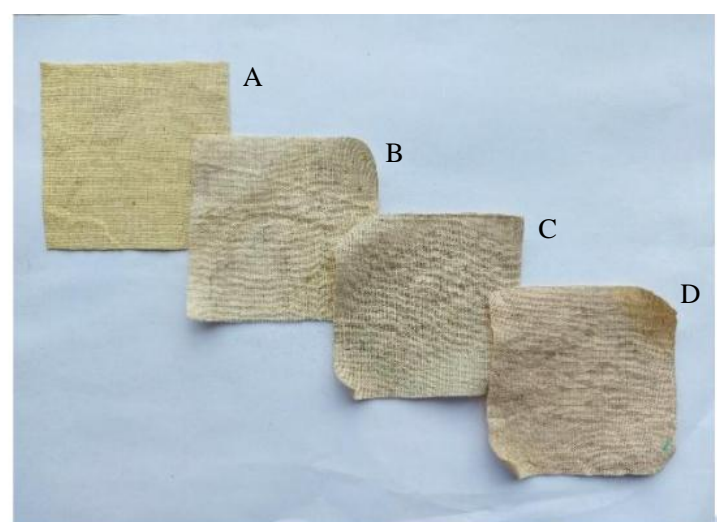

Fig. V.B.2-a, Turmeric dye with neem treatment A- Turmeric dyed fabric.

B- Turmeric dyed fabric dipped once in neem solution and dried.

C- Turmeric dyed fabric dipped twice in neem solution and dried.

D- Turmeric dyed fabric dipped thrice in neem solution and dried.

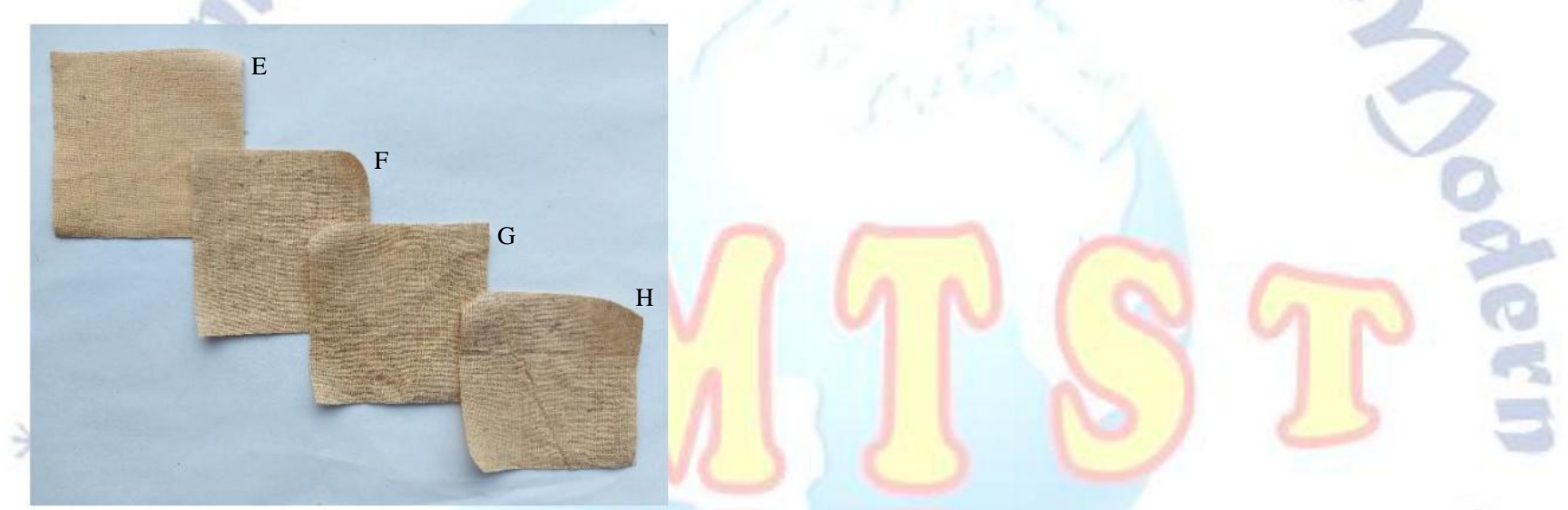

Fig. V.B.2-b, Pomegranate dye with neem

treatment E- Pomegranate skin dyed fabric.

F- Pomegranate skin dyed fabric dipped once in neem solution and dried.

G-Pomegranate skin dyed fabric dipped twice in neem solution and dried.

Pomegranate skin dyed fabric dipped thrice in neem solution and dried.

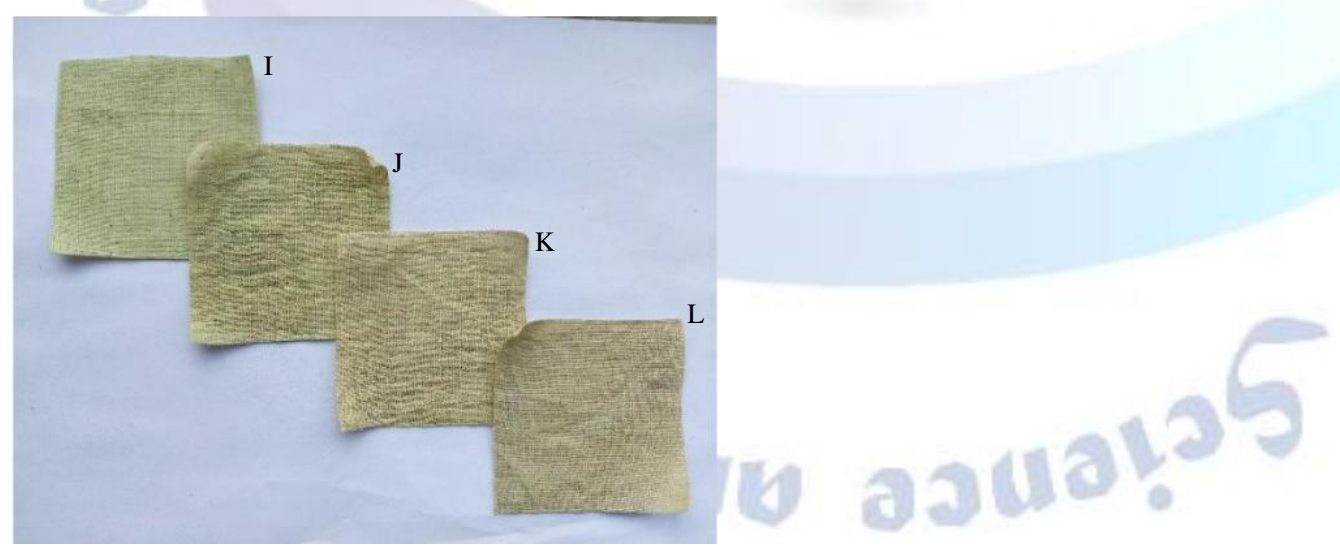

Fig. V.B.2-c, Peppermint dye with neem treatment

A- Peppermint dyed fabric.

B- Peppermint dyed fabric dipped once in neem solution and dried

C- Peppermint dyed fabric dipped twice in neem solution and dried.

D- Peppermint dyed fabric dipped thrice in neem solution and dried.

V.C: PRODUCT DEVELOPMENT 
The products are developed with $100 \%$ pure cotton fabric as it is abreathing fiber and favorable for health care applications requiring skin contact. It is also said to be the most suitable raw material forming the basis for shells and for the dust mite solution. After the medical dye treatment (mentioned above)is done on this fabric it is converted to a bedding collection/ wearable piece for the Patients and health workers providing them with its benefits.

The prototype of the bed collection using the above-mentioned process is shown below (Figures- V.C-d, V.C-e, V.C-f, V.C-g, V.C-h)

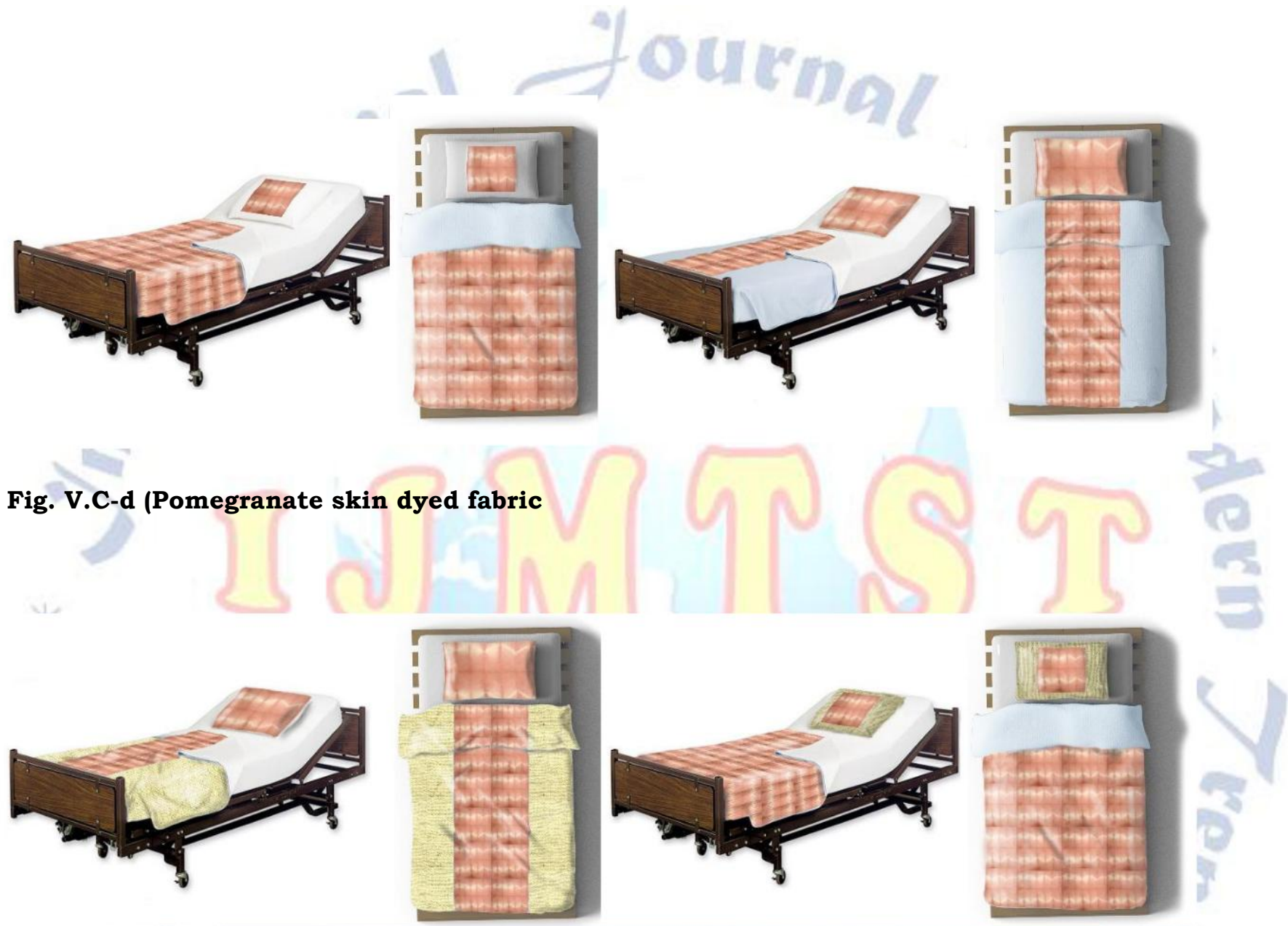

Fig. V.C-e (Turmeric dyed fabric bed collection+ Pomegranate skin dyed fabric)
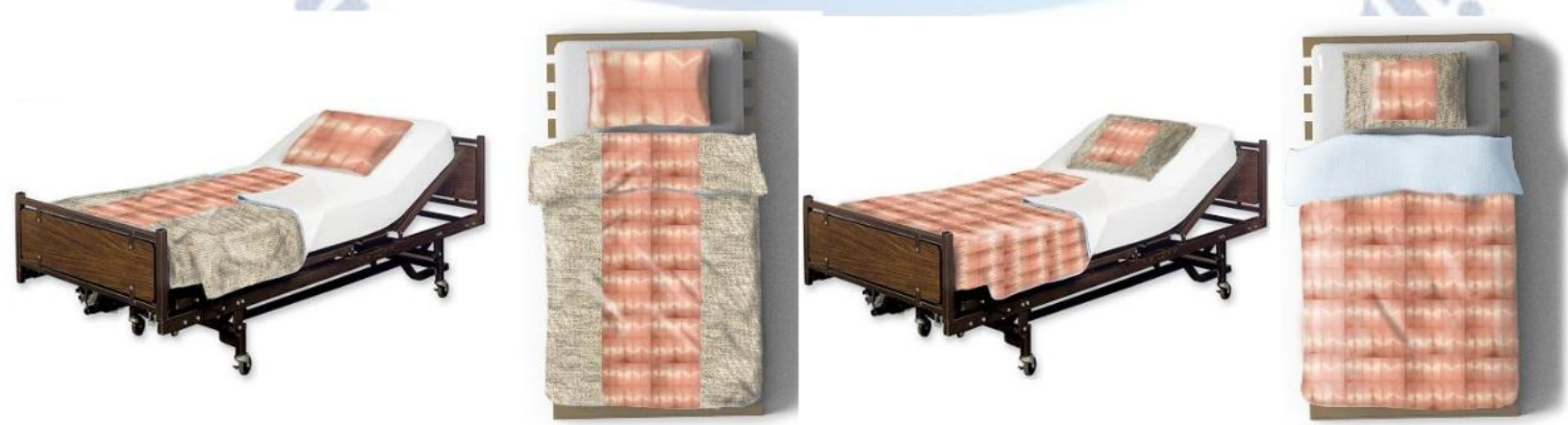

Fig. V.C-f (Turmeric dyed fabric dipped thrice in neem solution + Pomegranate skin dyed fabric - bed collection) 

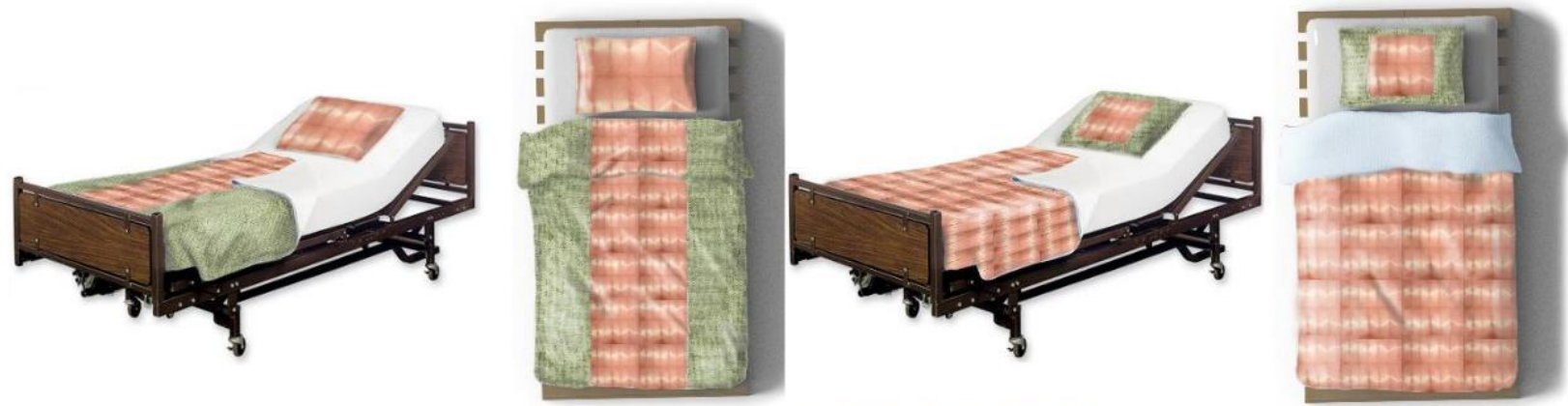

Fig. V.C-g (Peppermint dyed fabric bed collection+ Pomegranate skin dyed fabric)
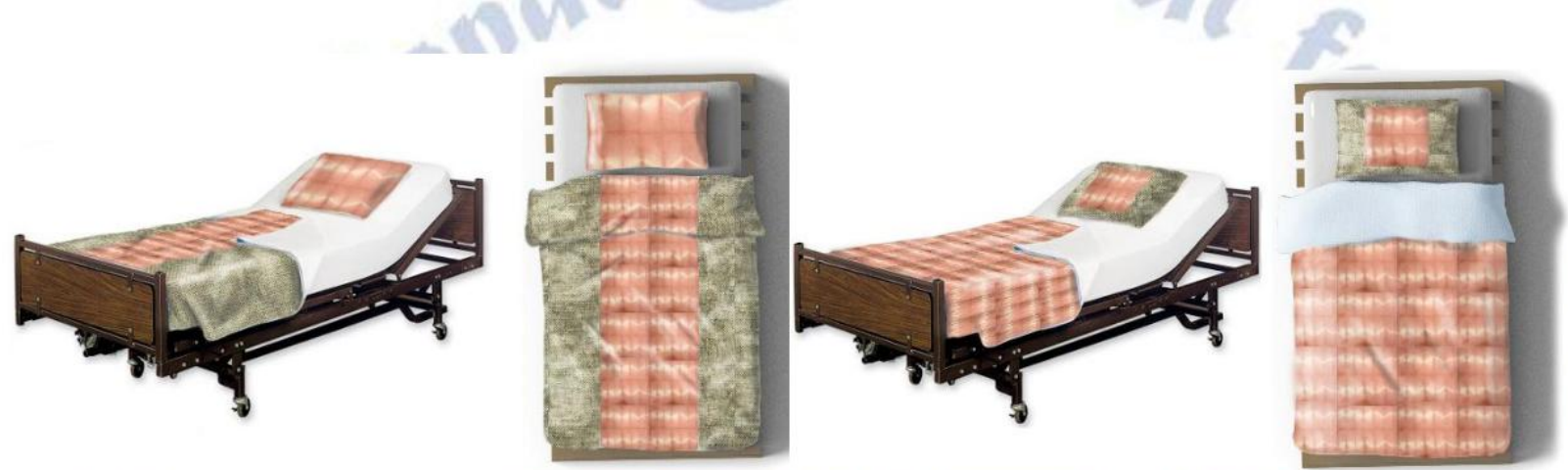

Fig. V.C-h (Peppermint dyed fabric dipped thrice in neem solution + Pomegranate skin dyed fabric - bed collection)

\section{MEDICINAL DYED BEDDING COLLECTION PROTOTYPE FOR HOSPITAL}

\section{CONCLUSION}

All the three chosen dyes including neem coating showed good substantively on the fabric $(100 \%$ natural). This textile product is planned to be made with a lot of health benefits and its usage depends on the theory of touch for the covid'19 patients and also for the workers in the hospital. Human body naturally heals itself when sleeping or meditatingthe therapeutic fabric when stays in contact with the skin pass to the body its medicinal merits. Thus, when the body is at rest, this clothing will work most effectively. It will help our body to stand against the harmful toxins, and germs about to enter the body through the skin. This home experimental textile will be more beneficial to use during this time of pandemic when a person needs to stay healthy and safe.

\section{REFERENCES}

1. International Journal of PharmTech Research- MEDICINAL IMPORTANCE OF NATURAL DYES, A REVIEW

2. Asian J. Adv. Basic Sci.: 2018, 6(3), 42-48- Medicinal Properties of Natural Colourants/Dyes from Plants

3. N. Wali, S. Dhavan, S. Garg, and S. N. Upadhyay, "Anti-inflammatory Effect of Neem Leaf Extract",Proceedingsof World Neem Conference, Bangalore, India,1993.(PDF) Experimental Study on Antimicrobial Activity of Silk Fabric Treated with Natural Dye Extract from Neem (Azadirachtaindica) Leaves.

4. J. Chem. Pharm. Res., 2010, 2(1): 62-72.Herbal Remedies of Azadirachtaindica and its Medicinal Application

5. I.V. Walker, proceedings of Medical Textile Conference., 1999, Bolton Institute, U.K., Publishing Co., Cambridge, 12 - 19

6. M. Mujumdar, A. S. Upadhye, and A. M. Pradhan, Ind.J. Pharm. Sci., 60, 363 (1998).

7. Fibers and Polymers 2018, Vol.19, No.9, 18801886 DOI $10.1007 / \mathrm{s} 12221-018-8239-3$

8. https://textination.de/en/node/14521

9. Ann Allergy Asthma Immunol. 2013 Dec; 111(6): 465-507.doi: 10.1016/j.anai.2013.09.018

10. U. Francine, U. Jeannette, and R. J. Pierre, J. Med. PlantsStudies, 3, 85 (2015).

11. aidic.it/cet/16/55/021.pdf

12. Journal of Photochemistry and Photobiology B: BiologyVolume 169, April 201

13. J Eng Fiber Fabr. 2015 Sep; 10(3): 180-190.

14. Asian Journal of Physical and Chemical Sciences

5(4): 1-16, 2018; Article no.AJOPACS.40614 ISSN: 2456-7779- Application of Novel Eco-friendly Natural Dye Extracted from Leaves of Neem on Silk Fabric. 